\section{Flexible registrar training}

Sir: Ruth Talbot's optimistic account of parttime higher professional training in child and adolescent psychiatry in Surrey (Psychiatric Bulletin, 17, 665-667) is of interest to all trainees considering a more 'flexible' approach to training.

In the West Midlands a specialised scheme for flexible (part-time) training for registrars in all specialities was advertised nationally in the spring of 1992. For psychiatrists, the interviews were held in October 1992 and funding made available from February 1993. Unfortunately, not all the training schemes in the region were made aware of this option by the clinical tutors and at the time of interview not all the posts were filled. Prior to this, the West Midlands was the only region in the country not to appoint SHOs and registrars onto a specialised flexible training scheme. Others, such as Oxford, have trained their junior psychiatrists flexibly for over 20 years.

The report of the Joint Working Party into Flexible Training (DoH, 1993) suggests that some senior medical staff view part-time training as a 'soft option' and 'inferior'. Ironically, as flexible posts are funded by the Department of Health and consequently supernumerary, trainees are welcomed onto clinical teams.

It is with some trepidation, therefore, that the security of a large well organised and integrated registrar rotation be rejected in favour of the less well established option of flexible training. Working out a time-table that provides a service role with space for an academic programme, setting boundaries without appearing too rigid and uncompromising and planning supernumerary slots on the on-call rota all involve delicate but firm negotiation.

It is reassuring to read that part-time training can be comprehensive and interesting in the presence of appropriate support and encouragement. Although new to the West Midlands we remain optimistic that, with increasing awareness and a working knowledge of part-time trainees, our role will become more established and the risk of marginalisation will be minimised. The co-ordinator of the rotation is enthusiastic in his support of flexible trainees and it is hoped that this will ensure the process of obtaining educational and manpower approval is facilitated where appropriate.

DEPARTMENT OF HEALTH (1993) The Report of the Joint Working Party on Flexible Training. NHS Management Executive.

KRISTINA HOFBERG, Reaside Clinic, Rubery, Birmingham B45 9BE; and RHONA SARGEANT, Uffculme Clinic, Moseley, Birmingham B13 8QD

\section{Auditing postgraduate meetings}

Sir: Most psychiatric hospitals have postgraduate educational programmes but their value is not generally monitored. Although trainees are under pressure to attend, consultants and other professionals may not, due to pressure of work or lack of interest, and it can be difficult to design a programme to meet everyone's needs.

At Blackberry Hill Hospital in Bristol, it was decided to audit meetings and with the aid of the audit department a form was designed to look at the degree of interest in the subject matter, its relevance to clinical practice, the quality of the speaker, visual aids and discussion and the relevance to exams for trainees. Scoring was on a visual analogue scale and forms are collated and results sent to the meetings co-ordinator and the presenter.

Looking at five months of returns we found that the range of interest varied between 4.6 and 9 (out of 10), relevance to practice between 4.7 and 10 , quality of speaker form 5.3 to 9 , that of visual aids from 3.8 to 10 and of discussion from 2.1 to 8.5. Relevance to exams varied between 3.3 and 9 with a smaller sample. There was variation between scores for different indices; good speakers did not always have good visual aids, for example.

Results indicate that this system has proved useful; during the period studied two speakers scored particularly highly; one has been invited back and it is hoped to invite the other later. Prior to this system some speakers were felt by the meetings co-ordinator not to be too good and it was difficult to know how to deal with this, particularly when the people were local. With audit, feedback comes from the whole audience and carries more validity and, because different areas are covered, a reasonable speaker who uses poor overheads, for example, can be alerted to this. The next step will be for the results to be presented to the audit meeting and for minimum standards to be set which meetings can then be measured against.

DanNy Allen, Blackberry Hill Hospital, Manor Road, Fishponds, Bristol BS16 2EW

\section{Management training - opportunities with the Open Business School}

Sir: We are encouraged during higher training to obtain experience in management. No clear guidance has emerged from strategic planning centres like the NHS Management Executive, or the NHS Training Directorate although the latter endorse business school courses (1991). Often enlightened trainees must take control and accept responsibility for their own training (Pedler et al, 1978). So where should such a 